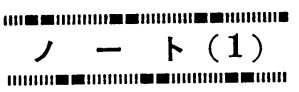

有機金属気相法によるへテロ・エ ピタキシャル ZnTe 薄膜の育成と 表・界面の特性

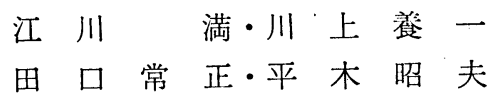

大阪大学工学部電気工学科 $\mathbf{T} 565$ 大阪府吹田市山田丘 $2-1$ (1988 年 2 月 1 日 受理)

\section{Growth, and Surface and Interface Characteristics of Hetero-Epitaxial ZnTe Films by Metalorganic Chemical- Vapour-Deposition}

Mitsuru EKAWA, Yoichi KAWAKAMI, Tsunemasa TAGUCHI and Akio HIRAKI

Department of Electrical Engineering, Faculty of Engineering, Osaka University

2-1 Yamadaoka, Suita, Osaka 565

(Received February 1, 1988)

Epitaxial layers of $\mathrm{ZnTe}$ were grown on (100) GaAs substrates by metalorganic chemicalvapour-deposition using dimethylzinc (DMZn) and dimethyltelluride (DMTe) as alkyl sources. The DMTe source was precracked because its high pyrolysis temperature is as high as $500^{\circ} \mathrm{C}$.

The grown layers have been characterized by using scanning electron microscopy, X-ray diffraction, Auger electron spectroscopy and 4.2 $\mathrm{K}$ PL techniques. It is shown that the photoluminescence spectra of $\mathrm{ZnTe}$ epilayers depend upon $(\mathrm{DMTe}) /(\mathrm{DMZn})$ concentration ratio and upon the substrate temperature.
II - VI 族化合物半導体である $\mathrm{ZnTe}$ は, 室温で, バン ドギャップが $2.26 \mathrm{eV}$ の直接遷移型半導体であるため, 緑色発光素子として有望である。特に, $\mathrm{ZnTe}$ は $\mathrm{p}$ 型 伝導を示す唯一の II - VI 族化合物であるため, 他の $\mathfrak{n}$ 型 半導体とのへテロ接合による $\mathrm{p}-\mathrm{n}$ 接合素子の作製が行 われている。従って, デバイスへの応用上, 電気伝導の 制御は重要であるが, バルク結晶では $\mathrm{n}$ 型伝導を得る ことは非常に困難である。しかしながら, 現在, 低温成 長 (約 $300^{\circ} \mathrm{C}$ ) が可能な有機金属気相法 (metalorganic chemical-vapour-deposition, 略して MOCVD) と分 子線エピタキシ法 (molecular-beam-epitaxy, 略して MBE) を用いることにより, ドナー不純物の添加で, 電 気伝導度を制御するととができるのではないかという期 待がかけられている。

一方, 赤外線センサへの応用のために, CdTe-HgTe, $\mathrm{ZnTe}-\mathrm{HgTe}$ 歪超格子に関する研究, および格子不整合 が小さくてその基板材料として有望な $\mathrm{CdZnTe}$ に関す る研究が, 最近活発になされている。以上のような観点 から, 我々は MOCVD 法により, 低温において, $\mathrm{GaAs}$ 基板上に $\mathrm{ZnTe}$ 薄膜の育成を試み, 成長過程の基 礎特性や表・界面の特性を調べた。

成長に使用した MOCVD 装置を Fig. 1 亿示す。原 料ガスとして, Zn のソースにはジメチル亜鈶 (DMZn) を, Te のソースにはジメチルテルル (DMTe) を用い た。DMTe は常温で液体であるので， $0^{\circ} \mathrm{C}$ 恒温槽中で 純化 $\mathrm{H}_{2}$ ガスによりバブリングを行い，ガスを得た。有 機 Te ガスの熱分解温度は高く, Mullin らの報告によ ると, DMTe, DETe は，それぞれ約 500, 400Cで熱分 解すると言われている1”。そてで，我々は DMTe の導 入口に Ta 線のヒータを設けて, 反応前に DMTe のク ラッキングを行った。

成長条件を Table 1 亿示す。基板には $\mathrm{GaAs}(100)$ 面

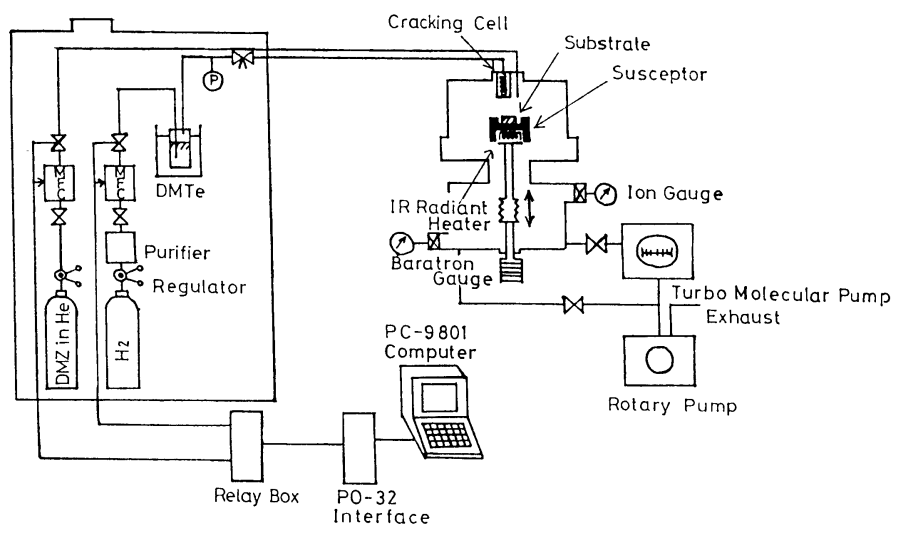

Fig. 1 Schematic diagram of the MOCVD system.

第 7 回表面科学講演大会（1987 年 12 月 23 日）にて発表。 
Table 1 Growth conditions.

\begin{tabular}{l|c}
\hline Substrate & GaAs $(100) \mathrm{ZnTe}(110)$ \\
Substrate temp. & $300-400^{\circ} \mathrm{C}$ \\
Cracking temp. & $350-450^{\circ} \mathrm{C}$ \\
Flow rate of DMZ & $0.9-4.5 \times 10^{-5} \mathrm{~mol} / \mathrm{min}$ \\
Flow rate of DMTe & $1.68 \times 10^{-5} \mathrm{~mol} / \mathrm{min}$ \\
Pressure & $0.4-0.7,5 \mathrm{Torr}$ \\
Distance between & \\
DMZ tube and susceptor & $7 \mathrm{~mm}$ \\
\hline
\end{tabular}

を用い, 前父理を行った後, 直ちにチャンバ内にセット し, $\mathrm{H}_{2}$ 父流中で, $550^{\circ} \mathrm{C}, 1$ 分聞のサーマルクリーニン グを行った。また，成長厈力は，減厌（0.4〜0.7 Torr） 下と 5 Torr トの 2 通りにした。

SEM に上るZnTe 薄膜の表面モルフォロジ一を Fig. 2 に示す。基板湿度はいずれも $350^{\circ} \mathrm{C}$ であるが, クラッキング温度は ( a ) $390^{\circ} \mathrm{C}$ ， ( b ) $450^{\circ} \mathrm{C}$ である。(a) では, クラッキング温度が低いために膜厚が薄く, 表面 は平担に見える。一方，（b）では，表面がグレイン状に

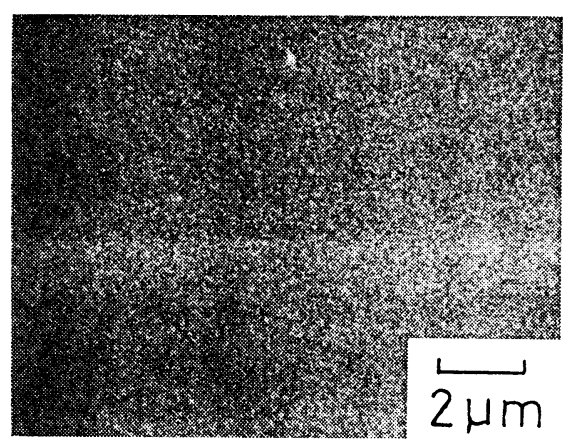

(a)

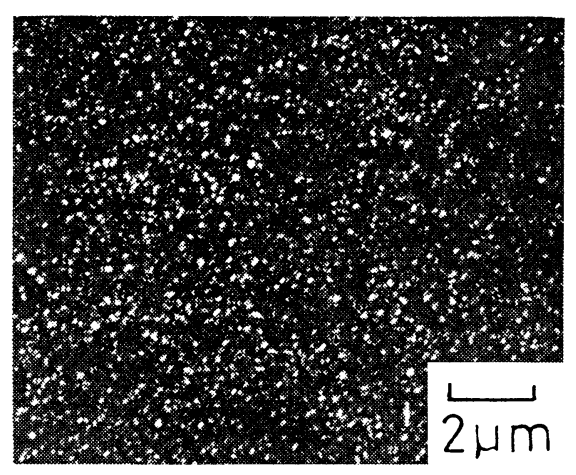

(b)

Fig. 2 SEM microphotograph of $\mathrm{ZnTe}$ film grown on a $(100) \mathrm{GaAs}$ substrate at $350^{\circ} \mathrm{C}$. Cracking temperature; (a) C.T. $390^{\circ} \mathrm{C}$, S. T. $350^{\circ} \mathrm{C}, t \approx 1000 \AA$ and (b) C. T. $450^{\circ} \mathrm{C}$, S. T. $350^{\circ} \mathrm{C}, t \approx 2500 \AA$

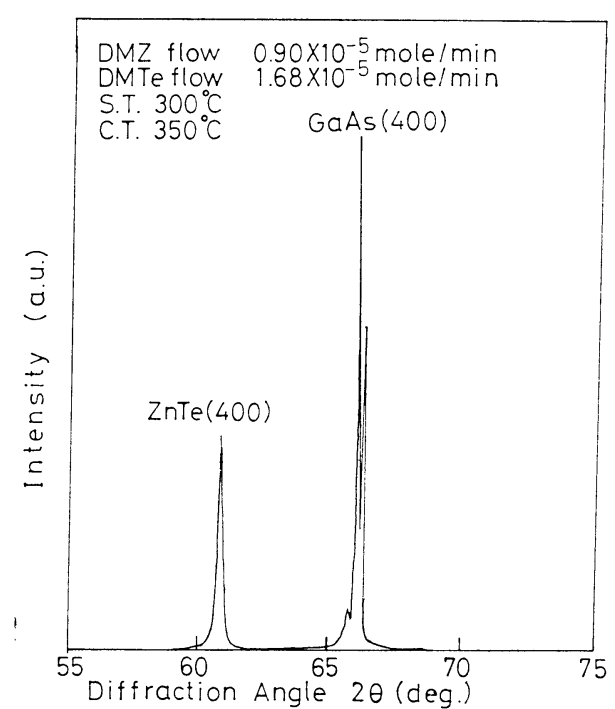

Fig. 3 X-ray diffraction spectrum of $\mathrm{ZnTe}$ epilayer grown on a (100) GaAs substrate.

見えるが，これは膜厚の違いのため，結晶粒界などの成 長過程を示しているか，あるいは DMTe が Ta 線と反 応し, $\mathrm{TaTe}_{2}$ のような化合物が表面に付着している可能 性がある。

基板温度 $300^{\circ} \mathrm{C}$, クラッキング温度 $350^{\circ} \mathrm{C}$, VI/II 比 2 で (100) GaAs 基板上に育成した $\mathrm{ZnTe}$ 薄膜の X 線 回折像を Fig. 3 亿示す。 $\mathrm{GaAs}(400)$ と $\mathrm{ZnTe}(400)$ によるピークが観察され, MOCVD 法により, ZnTe が エピタキシャル成長している。この回折像から得られる $\mathrm{ZnTe}$ の格子定数は $6.09 \AA$ となり, 彷来報告されている 值 $6.10 \AA$ とほぼ一致する。本条件下で育成した $\mathrm{ZnTe}$

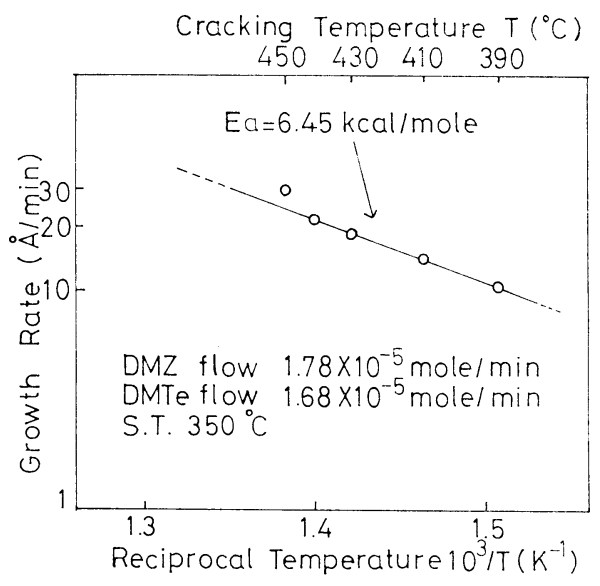

Fig. 4 Growth rate of $\mathrm{ZnTe}$ epilayers grown on (100) GaAs substrates as a function of cracking temperature. 


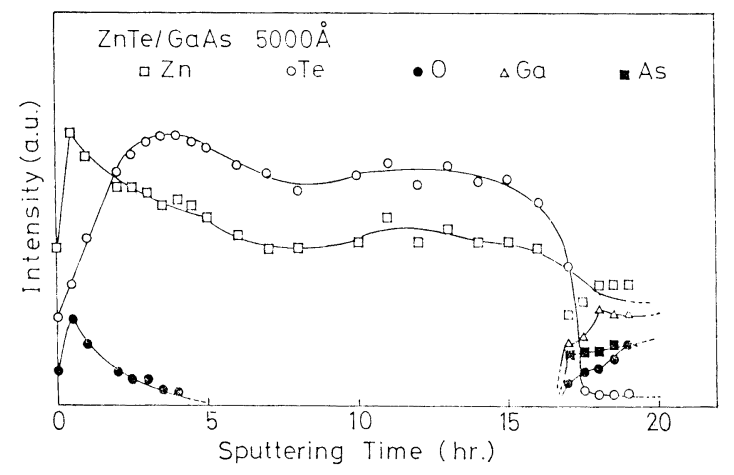

Fig. 5 Auger sputter profiling of $\mathrm{ZnTe}$ epilayer grown on a GaAs substrate.

膜は, $\mathrm{CdTe}$ と比較すると, 成長速度は 2 けた小さい。 これは, Te のソースに DMTe を用いたために, $390^{\circ} \mathrm{C}$ のクラッキング温度では, Te ガスの分解が十分に行わ れていないためであると考えられる。もし分解温度が $100^{\circ} \mathrm{C}$ 低い DETe を用いると，成長速度はかなり大きく なるものと予想される。これについては現在，実験を開 始している。

Fig. 4 は成長速度のクラッキング温度依存性を示し たものである。クラッキング温度の上昇と共に成長速度 む増加し, 活性化エネルギは $6.45 \mathrm{kcal} / \mathrm{mol}$ である。ク ラッキング温度が，DMTe の飽和熱分解温度に達する まで成長速度は增加するものと推測される。

次にオージェ電子分光法 (AES) により, $\mathrm{ZnTe} / \mathrm{GaAs}$ 界面と表面の評価を行った。Fig. 5 は GaAs 基板上 に育成した $\mathrm{ZnTe}$ 薄膜 (膜厚 $5000 \AA$ ) を, $5 \times 10^{-5} \mathrm{Torr}$, 加速電压 $2 \mathrm{keV}$ の $\mathrm{Ar}^{+}$ガスでスパッタした時の深さ方 向分布を示している。膜中における Zn $と \mathrm{Te}$ の組成の 均一性が良くないとと, 表面付近で酸素の信号が検出さ れることから, 表面には, $\mathrm{Te}$ の酸化膜が存在するとと がわかる。また, 界面では, 相互拡散が起こり, Zn が
基板中へ拡散していることがわかる。

$\mathrm{ZnTe}$ と $\mathrm{GaAs}$ の格子不整合は $8 \%$ と大きく, $\mathrm{ZnTe} /$ $\mathrm{GaAs}$ ヘテロ膜においてフォトルミネッセンス (PL) が 観察されたという報告は, MOCVD法では我々の知るか ぎり皆無である。成辰圧力 5 Torr で（100） GaAs 基板 上に育成した $\mathrm{ZnTe}$ 薄膜の $4.2 \mathrm{~K}$ における PLを Fig. 6 に示す。乙こで, 基板温度は $350^{\circ} \mathrm{C}$, クラッキング温 度は $400^{\circ} \mathrm{C}$, そしてVI/II比は 2 で, 膜厚は $5000 \AA$ であ った。バルクの $\mathrm{ZnTe}$ は, $2.375 \mathrm{eV}$ に中性アクセプタ である $\mathrm{Zn}$ の空孔 $\mathrm{V}_{\mathrm{Zn}}$ に束縛された励起子による発光 線を示すが2)，てのエピタキシャル膜の場合， $2.364 \mathrm{eV}$ に中性アクセプタに束縛された励起子による強い発光線 $\left(\mathrm{A}^{0}, \mathrm{X}\right)$ とその LO一フォノンレプリカが現れる。し かしながら，その局在中心の起源は複合欠陷であろうと 推定されている2)。また，約 $650 \mathrm{~nm}$ を中心に酸素束縛 励起子 (OBE) 発光带が観測されるが, この発光強度 は, $2.364 \mathrm{eV}$ のものと比較するとかなり弱い。OBEに よる発光は, 酸素が $\mathrm{Te}$ 位置と置換して等電子トラッ プとして働くためである。酸素の混入の原因は, 元々, 原料ガスに酸素が含まれている，あるいは $\mathrm{ZnTe}$ 薄膜

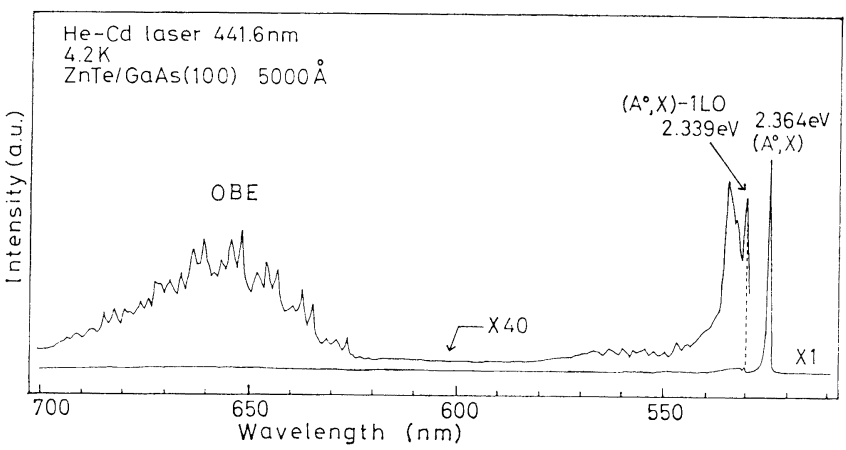

Fig. $64.2 \mathrm{~K}$ photoluminescence spectrum of $\mathrm{ZnTe}$ epilayer grown on a $\mathrm{GaAs}$ substrate at $350^{\circ} \mathrm{C}$. 


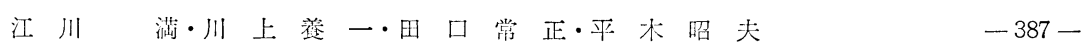

が, 成長後, 大父化にさらされて酸化されやすいためで あるか，いずれかが考えられる。しかしながら，VI/II 比を 1 にして, PL を観察したところ, $2.364 \mathrm{eV}$ の発光 が弱くなり，2.375 eV にもわずかながら発光が観察さ れた。徒って, ZnTe 薄膜の PL は, VI/II 比や基板温度 に強く依存するものと考えられる。成長条件之 PL お よび歪についての諳細な研究は, 我々の他の論文を参落 にされたい゙〉。

本研究は, 一部, 文部省科学研究費一般研究 (c)
No. 62550013 によっての援助を受けたむのである。

\section{文 献}

1) J. B. Mullin, S. J. C. Irvine and D. J. Ashen: J. Crystal Growth 55, 92 (1981).

2) 浜田 健: 大阪大学大学院修士論文 (1981).

3) M. Ekawa, Y. Kawakami, T. Taguchi and A. Hiraki：第 4 回 MOCVD 国際学全発表 (1988) to be published J. Cryst. Growth (1888). 